\title{
An Internally Consistent Approach To Common Stock Valuation
}

\author{
Larry Gorman, (Email: lgorman@ calpoly.edu), California Polytechnic State University ${ }^{1}$
}

\begin{abstract}
A modern corporate finance curriculum typically extends the one-stage Gordon (1962) dividend discount model into a multi-stage environment. In such instances, each regime of constant dividend growth defines a distinct stage. The rate of sustainable dividend growth in each stage is typically determined by specifying the firm's return on asset (ROA) and plowback $(P B)$ ratios in each stage, and then computing the implied dividend growth rate as $\mathrm{g}=\mathrm{ROA} \cdot \mathrm{PB}$.
\end{abstract}

In a two-stage problem, current convention typically advocates that the first dividend in the second stage should equal the last dividend in the first stage, multiplied by $1+g_{2}$, where $g_{2}$ is the growth rate of dividends in the second stage. We show that the dividend stream generated with this methodology is inconsistent with the ROA and plowback assumptions used previously to compute $g_{2}$. The implication is that the conventional pricing methodology results in stock valuations that are inconsistent with ROA and PB assumptions. For a common textbook problem, we demonstrate pricing errors on the order of $30 \%$. In order to address the issue, we provide an alternative pricing methodology that results in valuations that are consistent with underlying assumptions.

Pedagogically, when the proposed approach is contrasted with the traditional approach, the student is forced to develop a deeper fundamental understanding of how stock valuation relates to ( $i)$ operational efficiency, (ii) dividend policy, and (iii) the economic environment in which the firm competes.

\section{Introduction}

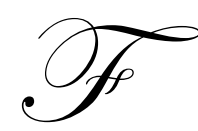

or more than thirty years, a typical curriculum in corporate finance has included a discussion of the one stage dividend discount model, often referred to as the Gordon (1962) Model. An important expansion upon this model is the valuation of common stock in which more than one stage (or regime) of dividend growth occurs. Investment and corporate finance textbooks motivate both the single stage, and the multi-stage models with simple dynamics for achieving dividend growth. We demonstrate that the "traditional" method of computing dividends in a multi-stage environment is logically inconsistent at the transitionary periods between dividend growth stages. This results in an assumed dividend stream in the latter stage(s) that is literally not feasible, and hence leads to price calculations that are erroneous. We propose a simple, internally consistent alternative pricing methodology that results in the a price consistent with the underlying assumptions.

\section{Model of Dividend Growth}

Many textbooks provide a model of firm operations in order to motivate the dividend generation process. The posited model of firm operations is typically as follows.

Readers with comments or questions are encouraged to contact the author via email. Suppose a particular dividend growth regime, or stage, is expected to last $\mathrm{T}$ years. ${ }^{2}$ Assume that within this stage

\footnotetext{
${ }^{1}$ I wish to thank Cyrus Ramezani and Robert Simon for helpful comments. All errors remain my own.
} 
the return on assets, ROA, and the firm's plowback ratio, $\mathrm{PB}$, is constant. Let the firm's profit generated from time $\mathrm{t}-1$ to time $\mathrm{t}$ be denoted $\mathrm{PAT}_{\mathrm{t}}$. At the beginning of the regime, assume that the level of productive assets in place is $\mathrm{A}_{0}$. Since by definition $\mathrm{ROA} \equiv \mathrm{PAT}_{\mathrm{t}} / \mathrm{A}_{\mathrm{t}-1}$, we know that the profit after tax in the first period of operations, $\mathrm{PAT}_{1}$ will equal ROA $\cdot \mathrm{A}_{0}$. Of this profit, a proportion (defined by the plowback ratio) is retained by the firm, and the remainder is paid out as a dividend $\mathrm{D}_{1}\left(=\mathrm{PAT}_{1} \cdot\{1-\mathrm{PB}\}\right)$. Therefore, the level of productive assets in place at time 1 , $A_{1}$, equals $A_{0}+\mathrm{PAT}_{1} \cdot \mathrm{PB}_{\mathrm{t}}$. The firm is expected to continue operating in this manner until the end of the stage, at time T. ${ }^{3}$

The expression for the growth rate of dividends in the above scenario within the stage, is derived as follows: The change in productive assets (i.e. retained earnings) in any period, $\mathrm{t}$, is $\mathrm{PAT}_{\mathrm{t}} \cdot \mathrm{PB}$. When this is divided by the level of assets in place at time $t-1$, the percentage change (i.e. the growth rate) of productive assets is obtained to be $\{\mathrm{PATt} \cdot \mathrm{PB}\} / \mathrm{A}_{\mathrm{t}-1}$. However $\mathrm{PAT}_{\mathrm{t}} / \mathrm{A}_{\mathrm{t}-1}$ is by definition equal to ROA, and hence the growth rate of productive assets can also be written as $\% \Delta \mathrm{A}=\mathrm{ROA} \cdot \mathrm{PB}$.

With ROA constant, and defined as the ratio $\mathrm{PAT}_{\mathrm{t}} / \mathrm{A}_{\mathrm{t}-1}$, it must be true that $\% \Delta \mathrm{PAT}=\% \Delta \mathrm{A}$ (i.e. if PAT increases by $20 \%$ then so must $\mathrm{A}$ in order for the ratio to remain constant). Therefore, ROA $\cdot \mathrm{PB}$ is also equal to $\% \Delta$ PAT .

The payout ratio, defined as $\mathrm{D}_{t} / \mathrm{PAT}_{\mathrm{t}}$, is also assumed to be constant within the stage. In order for this ratio to remain constant it must be true that $\% \Delta \mathrm{PAT}=\% \Delta \mathrm{D}$. Therefore, we know that ROA $\cdot \mathrm{PB}$ is also equal to $\% \Delta \mathrm{D}$.

Overall we have $\% \Delta \mathrm{A}=\% \Delta \mathrm{PAT}=\% \Delta \mathrm{D}=\mathrm{ROA} \cdot \mathrm{PB}$. That is, the growth rate of dividends, g, equals the product of ROA and PB. We now have an expression for the growth rate of dividends within a particular regime. ${ }^{4}$ Unfortunately, this says nothing about the growth rate of dividends at transition points between regimes. We show below that inadequately addressing dividend generation issues in the transitionary period between dividend regimes, results in substantial pricing errors.

\section{Multi-Stage Dividend Growth - The Traditional Solution}

The traditional approach is easily demonstrated with an example. Consider a two-stage dividend growth problem: Firm $\mathrm{Z}$ just paid a dividend of $\$ 1.00 /$ share and is will have an ROA of $20 \%$ and a plowback of $50 \%$ for the first 2 years. Thereafter, Firm $\mathrm{Z}$ will have an ROA of $10 \%$ and a plowback of $30 \%$. Assume the discount rate is $10 \%$. Find the price of Firm Z's stock. The problem is depicted in Table 1.

Table 1

Firm Z, 2-Stage Sample Problem

\begin{tabular}{|l|c|c|}
\hline & Stage 1 & Stage 2 \\
\hline Years & 1,2 & $3,4,5, \ldots, \infty$ \\
\hline ROA & 0.20 & 0.10 \\
\hline Plowback (PB) & 0.50 & 0.30 \\
\hline g (= ROA.PB) & 0.10 & 0.03 \\
\hline
\end{tabular}

The traditional solution to this problem computes the dividend growth rate, $\mathrm{g}=\mathrm{ROA} \cdot \mathrm{PB}$, in stage 1 as

\footnotetext{
${ }^{2}$ In order to simplify our discussion, we will assume that dividends occur only once per year, and hence "one period" should be thought to imply "one year." The same arguments extend to quarterly or monthly dividends.

${ }^{3}$ That is, the assets in place at the beginning of each year generate a profit after tax defined by ROA. Of these profits, a proportion is paid out as dividends, and the remaining proportion is re-invested in additional productive assets. These assets are now in place at the beginning of the subsequent year, and the cycle continues.

${ }^{4}$ In addition, it is clear that within a particular regime, the level of productive assets and profits grow at the same rate as dividends.

${ }^{5}$ Alternatively, for textbooks that do not cover the $\mathrm{g}=\mathrm{ROA} \cdot \mathrm{PB}$ model, the problem is typically stated as: Firm $\mathrm{Z}$ just paid a dividend of

$\$ 1.00 /$ share and these dividends are expected to grow at a $10 \%$ rate for the next 2 years. Thereafter, dividends are expected to grow at a $3 \%$ rate forever. Find the current price of Firm Z's stock.
} 
$10 \%$, and computes the dividends at time 1 and 2 to be $\$ 1.10$ and $\$ 1.21$. For dividends beyond year 2 , the stage 2 dividend growth rate of $3 \%$ is computed. This $3 \%$ rate is used to compute a dividend in year 3 of $\$ 1.246$ $(=\$ 1.21 \cdot 1.03)$, with subsequent dividends growing at 3\% thereafter. We show that for the firm under study, this dividend stream is impossible to attain, and hence its use results in incorrect stock valuations. For the sample problem, the pricing error is nearly $30 \%$. The inconsistency associated with the traditional solution is exposed by investigating how dividends are generated in the transitory period between stage 1 and 2.

\section{The Proposed Alternative Solution}

Assume that Firm $\mathrm{Z}$ currently has an economic value of productive assets $\left(\mathrm{A}_{0}\right)$ equal to $\$ 11 /$ share, and that the assumptions of Table 1 hold. In this case, the 20\% ROA implies a level of profits in year 1 of $\$ 2.20 /$ share, 50\% of which is paid out as dividends $\left(D_{1}=\$ 1.10\right)$, and $50 \%$ is plowed back into the firm to purchase additional productive assets. At the beginning of year 2 , there is $\$ 12.10(=\$ 11+\$ 1.10)$ of productive assets in place, and again a return of $20 \%$ is earned, implying a profit of $\$ 2.42$ per share, half of which is paid in dividends $\left(D_{2}=\$ 1.21\right)$, and half of which is plowed back. Therefore at the end of year 2 the level of productive assets in place is $\$ 13.31(=\$ 12.10+$ $\$ 1.21)$.

In the next year, which is the first year of the second stage, a productive asset base of $\$ 13.31$ exists and these assets earn an ROA of $10 \%$, implying that profits in year 3 will be $\$ 1.331$. Of these profits, $70 \%$ are paid out as a year 3 dividend while the remaining $30 \%$ are plowed back into the firm's productive asset base. This implies a year 3 dividend of $\$ .932(=\$ 1.331 \cdot .70)$. Beyond year 3, it is easy to show that stage two ROA and plowback assumptions (of $10 \%$ and $30 \%$ respectively) imply that all subsequent dividends will grow at a $3 \%$ rate forever. Mathematically, if $\mathrm{D}_{3}$ is forced to exceed $\$ .932$ (as it does in the traditional solution) then the subsequent growth rate must be less than 3\%. If one ignores this issue, as the traditional solution does, and imposes both $\mathrm{D}_{3}=\$ 1.246$ and $3 \%$ growth, then the assumed dividend stream is impossible to achieve and its use produces erroneous stock prices.

As shown in Figure 1, the traditional method of generating dividends imposes $\mathrm{D}_{3}=\$ 1.246$ growing thereafter at an unsustainable $3 \%$ rate, whereas the proposed method employs $\mathrm{D}_{3}=\$ .932$ growing thereafter at a sustainable $3 \%$ rate. The traditional solution results in a stock price of $\$ 16.71$ /share while the proposed solution results in an internally consistent stock price of $\$ 13.00 /$ share - a $29 \%$ difference!

\section{Explaining the Discrepancy in Price}

Many textbooks advocate using a dividend level, $\mathrm{D}_{3}$, of $\$ 1.246$, growing at $3 \%$ thereafter. ${ }^{6}$ That is, current convention advocates that the first dividend in the second stage should be 3\% greater than the last dividend in the first stage $(\$ 1.246=\$ 1.21 \cdot 1.03)$. However, the previous section makes it clear that a productive asset base, $\mathrm{A}_{2}$, of $\$ 13.31$ share exposed to $10 \%$ ROA, and a $70 \%$ payout, can only support a dividend in year 3 of $\$ .932$ growing at $3 \%$, not $\$ 1.246$ growing at 3\%. Although the firm is certainly capable of imposing a dividend, $\mathrm{D}_{3}$, of $\$ 1.246$ (by drawing down assets), its stage two ROA of $10 \%$, and plowback of $30 \%$ is insufficient to support $3 \%$ dividend growth thereafter.

\section{Figure 1 \\ "Traditional versus Proposed Solution"}

\footnotetext{
${ }^{6}$ Textbooks advocating this approach include: Fundamentals of Corporate Finance, 2001, $3^{\text {rd }}$ ed., by Brealey, Myers, and Marcus pp 147-8. Financial Management, Theory and Practice, 2002, $1^{\text {st }}$ ed., by Brigham and Ehrnhardt, pp 395-6. Fundamentals of Financial Management, 1999, $8^{\text {th }}$ ed., by Brigham and Houston, pp 314-5. Modern Corporate Finance, Theory and Practice, 1999, $2^{\text {nd }}$ ed., by D. Chambers and N. Lacey, pp 137-8. Principles of Financial Management, 1998, $2^{\text {nd }}$ ed., by Emery, Finnerty, and Stowe, pp 172-4. Corporate Financial Management, 1997, by D. Emery and J. Finnerty, pp 151-3. Foundations of Corporate Finance, 2002, by Hickman, Hunter, and Byrd, pp142-3. Principles of Corporate Finance, 1998, $2^{\text {nd }}$ Ed, by H. Levy, pp 489. Practical Financial Management, 2000, $2^{\text {nd }}$ ed., by W. Lasher, pp 219-20. Financial Management, 2000, $1^{\text {st }}$ ed., by Lewellen, Halloran, Lanser, pp 227-9. Contemporary Financial Management, 2001, $8^{\text {th }}$ ed., by Moyer, McGuigan, and Kretow, pp 287-8, Financial Management and Policy, 1998, $11^{\text {th }}$ ed., by J.C. Van Horne, pp 30-2.
} 


\section{The Differing Dividend Timelines and Computed Price}

The first timeline describes the dividend stream generated by the traditional methodology. It results in a computed price of $\$ 16.71 /$ share. The second timeline describes the dividend stream generated by the proposed methodology. It results in a computed price of $\$ 13.00 /$ share.

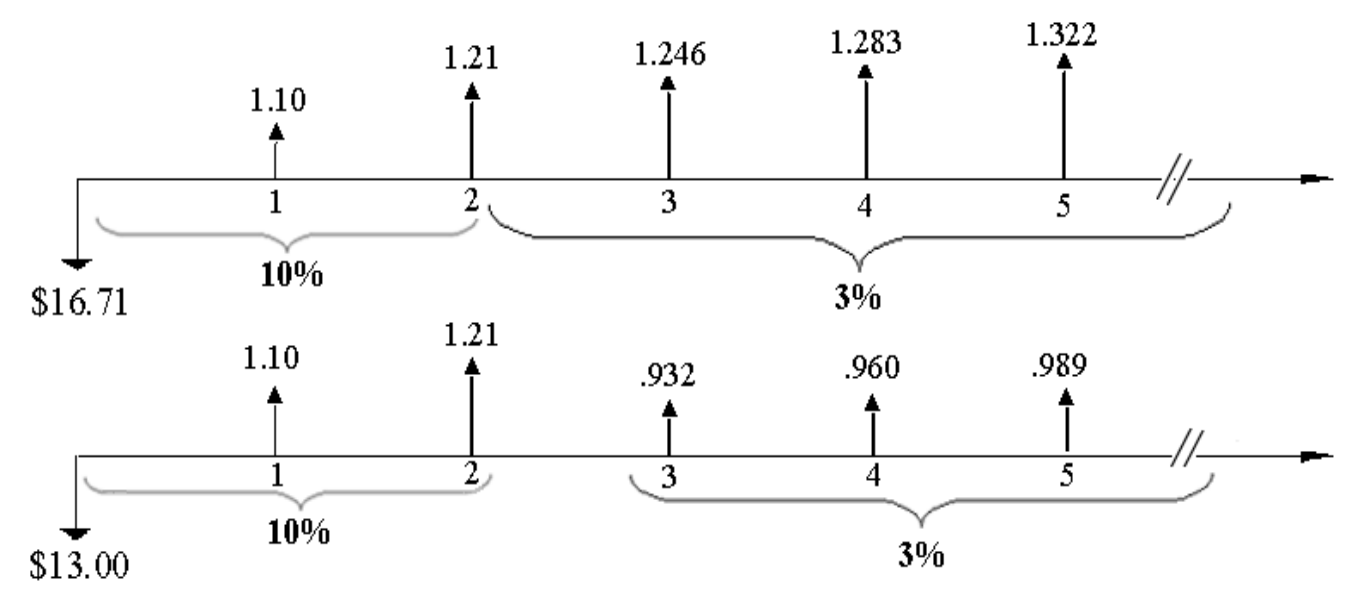

There are essentially two explanations for describing how the firm could impose an abnormally large dividend of $\$ 1.246$. First, the firm could - somehow - earn an abnormally large ROA from time 2 to 3 while maintaining the plowback ratio at $30 \%$. Second, the firm can maintain an ROA of $10 \%$ and temporarily increase the payout ratio. Both explanations require exaggerated (extraneous) assumptions. In either case, changing the assumed level of either ROA or plowback is equivalent to redefining the original problem, and hence it is not congruent with the problem as depicted in Table 1. In addition, in either case, after the firm reverts back to an ROA of $10 \%$ and a plowback of $30 \%$, the next dividend will be $\mathrm{D}_{4}=\$ .938$, which is a $24.77 \%$ reduction relative to the previously imposed dividend of $\mathrm{D}_{3}=\$ 1.246$, not a $3 \%$ increase! In short, a stage two ROA of $10 \%$ and a plowback of $30 \%$ cannot support the traditionally assumed dividend stream. ${ }^{7}$

Table 2, Panel A provides quantitative detail regarding the proposed solution. ${ }^{8}$ Alternatively, Panel B details what occurs, if instead of the proposed dividend process, an abnormally large dividend of $\$ 1.246$ is imposed in period 3 while maintaining the stage 2 ROA and plowback levels at $10 \%$ and $30 \%$ respectively. In both cases, the equilibrium stock price is $\$ 13.00 /$ share, not $\$ 16.71 /$ share as implied by the traditional approach. In other words, it is not possible to justify a price of $\$ 16.71$ even if management temporarily imposes abnormally large dividends (at the expense of reducing the level of productive assets). The only price that is consistent with the assumptions of Table 1 is $\$ 13.00$ per share.

Table 2

\footnotetext{
${ }^{7}$ Of course some firm could produce the entire traditionally derived dividend stream depicted in Figure 1. However, in order to support such a dividend process, the implied ROA and plowback evolutions will bear little resemblance to the problem depicted in Table 1 . By necessity, any firm able to produce the entire traditionally derived dividend stream, must have a relatively generous ROA in year 2 and beyond. Such a generous ROA is not congruent with the example under study as depicted in Table 1. Furthermore, the (new) higher ROA would imply a new stage two value of $\mathrm{g}=\mathrm{ROA} \cdot \mathrm{PB}$, which would be inconsistent with the $3 \%$ dividend growth mandated by the traditional approach.

${ }^{8}$ We assume a discount rate of $10 \%$.
} 
Panel A

Details of the proposed solution to the 2 stage dividend problem outlined in Table 1 .

For an assumed discount rate of $10 \%$, the equilibrium price is $\$ 13.00$ / share.

\begin{tabular}{|c|c|c|c|c|c|c|c|c|c|c|c|}
\hline Time & 0 & 1 & 2 & 3 & 4 & 5 & 6 & 7 & 8 & 9 & 10 \\
\hline \multicolumn{12}{|l|}{ Assumptions: } \\
\hline ROA & & $20.0 \%$ & $20.0 \%$ & $10.0 \%$ & $10.0 \%$ & $10.0 \%$ & $10.0 \%$ & $10.0 \%$ & $10.0 \%$ & $10.0 \%$ & $10.0 \%$ \\
\hline Payout & & $50.0 \%$ & $50.0 \%$ & $70.0 \%$ & $70.0 \%$ & $70.0 \%$ & $70.0 \%$ & $70.0 \%$ & $70.0 \%$ & $70.0 \%$ & $70.0 \%$ \\
\hline Plowback (PB) & & $50.0 \%$ & $50.0 \%$ & $30.0 \%$ & $30.0 \%$ & $30.0 \%$ & $30.0 \%$ & $30.0 \%$ & $30.0 \%$ & $30.0 \%$ & $30.0 \%$ \\
\hline \multicolumn{12}{|l|}{ Calculations: } \\
\hline Assets(t-1) & $\$ 11.00$ & $\$ 12.10$ & $\$ 13.31$ & $\$ 13.71$ & $\$ 14.12$ & $\$ 14.54$ & $\$ 14.98$ & $\$ 15.43$ & $\$ 15.89$ & $\$ 16.37$ & $\$ 16.86$ \\
\hline$x \operatorname{ROA}(\mathrm{t})$ & & $20.0 \%$ & $20.0 \%$ & $10.0 \%$ & $10.0 \%$ & $10.0 \%$ & $10.0 \%$ & $10.0 \%$ & $10.0 \%$ & $10.0 \%$ & $10.0 \%$ \\
\hline$=$ Profit $(\mathrm{t})$ & & $\$ 2.200$ & $\$ 2.420$ & $\$ 1.331$ & $\$ 1.371$ & $\$ 1.412$ & $\$ 1.454$ & $\$ 1.498$ & $\$ 1.543$ & $\$ 1.589$ & $\$ 1.637$ \\
\hline x Payout(t) & & $50.0 \%$ & $50.0 \%$ & $70.0 \%$ & $70.0 \%$ & $70.0 \%$ & $70.0 \%$ & $70.0 \%$ & $70.0 \%$ & $70.0 \%$ & $70.0 \%$ \\
\hline$=$ Dividends $(\mathrm{t})$ & & $\$ 1.100$ & $\$ 1.210$ & $\$ 0.932$ & $\$ 0.960$ & $\$ 0.988$ & $\$ 1.018$ & $\$ 1.049$ & $\$ 1.080$ & $\$ 1.112$ & $\$ 1.146$ \\
\hline Stock Price / Sh. & $\$ 13.00$ & $\$ 13.20$ & $\$ 13.31$ & $\$ 13.71$ & $\$ 14.12$ & $\$ 14.54$ & $\$ 14.98$ & $\$ 15.43$ & $\$ 15.89$ & $\$ 16.37$ & $\$ 16.86$ \\
\hline Capital Gain & & $1.54 \%$ & $0.83 \%$ & $3.00 \%$ & $3.00 \%$ & $3.00 \%$ & $3.00 \%$ & $3.00 \%$ & $3.00 \%$ & $3.00 \%$ & $3.00 \%$ \\
\hline Dividend Yield & & $8.46 \%$ & $9.17 \%$ & $7.00 \%$ & $7.00 \%$ & $7.00 \%$ & $7.00 \%$ & $7.00 \%$ & $7.00 \%$ & $7.00 \%$ & $7.00 \%$ \\
\hline Overall Return & & $10.00 \%$ & $10.00 \%$ & $10.00 \%$ & $10.00 \%$ & $10.00 \%$ & $10.00 \%$ & $10.00 \%$ & $10.00 \%$ & $10.00 \%$ & $10.00 \%$ \\
\hline$\%$ Chg. & & $10.00 \%$ & $10.00 \%$ & $3.00 \%$ & $3.00 \%$ & $3.00 \%$ & $3.00 \%$ & $3.00 \%$ & $3.00 \%$ & $3.00 \%$ & $3.00 \%$ \\
\hline$\%$ Chg. In Profits & & $N / A$ & $10.00 \%$ & $-45.00 \%$ & $3.00 \%$ & $3.00 \%$ & $3.00 \%$ & $3.00 \%$ & $3.00 \%$ & $3.00 \%$ & $3.00 \%$ \\
\hline$\%$ Chg. In Dividends & & $N / A$ & $10.00 \%$ & $-23.00 \%$ & $3.00 \%$ & $3.00 \%$ & $3.00 \%$ & $3.00 \%$ & $3.00 \%$ & $3.00 \%$ & $3.00 \%$ \\
\hline
\end{tabular}

\section{Panel B}

Details of the proposed solution with a dividend of $\$ 1.246$ imposed in year 3 .

For an assumed discount rate of $10 \%$, the equilibrium price is $\$ 13.00$ / share

\begin{tabular}{|c|c|c|c|c|c|c|c|c|c|c|c|}
\hline Time & 0 & 1 & 2 & 3 & 4 & 5 & 6 & 7 & 8 & 9 & 10 \\
\hline \multicolumn{12}{|l|}{ Assumptions: } \\
\hline ROA & & $20.0 \%$ & $20.0 \%$ & $10.0 \%$ & $10.0 \%$ & $10.0 \%$ & $10.0 \%$ & $10.0 \%$ & $10.0 \%$ & $10.0 \%$ & $10.0 \%$ \\
\hline Payout & & $50.0 \%$ & $50.0 \%$ & $93.6 \%$ & $70.0 \%$ & $70.0 \%$ & $70.0 \%$ & $70.0 \%$ & $70.0 \%$ & $70.0 \%$ & $70.0 \%$ \\
\hline Plowback (PB) & & $50.0 \%$ & $50.0 \%$ & $6.4 \%$ & $30.0 \%$ & $30.0 \%$ & $30.0 \%$ & $30.0 \%$ & $30.0 \%$ & $30.0 \%$ & $30.0 \%$ \\
\hline \multicolumn{12}{|l|}{ Calculations: } \\
\hline Assets $(\mathrm{t}-1)$ & $\$ 11.00$ & $\$ 12.10$ & $\$ 13.31$ & $\$ 13.39$ & $\$ 13.80$ & $\$ 14.21$ & $\$ 14.64$ & $\$ 15.08$ & $\$ 15.53$ & $\$ 15.99$ & $\$ 16.47$ \\
\hline$x \operatorname{ROA}(\mathrm{t})$ & & $20.0 \%$ & $20.0 \%$ & $10.0 \%$ & $10.0 \%$ & $10.0 \%$ & $10.0 \%$ & $10.0 \%$ & $10.0 \%$ & $10.0 \%$ & $10.0 \%$ \\
\hline$=$ Profit $(\mathrm{t})$ & & $\$ 2.200$ & $\$ 2.420$ & $\$ 1.331$ & $\$ 1.339$ & $\$ 1.380$ & $\$ 1.421$ & $\$ 1.464$ & $\$ 1.508$ & $\$ 1.553$ & $\$ 1.599$ \\
\hline x Payout(t) & & $50.0 \%$ & $50.0 \%$ & $93.6 \%$ & $70.0 \%$ & $70.0 \%$ & $70.0 \%$ & $70.0 \%$ & $70.0 \%$ & $70.0 \%$ & $70.0 \%$ \\
\hline = Dividends(t) & & $\$ 1.100$ & $\$ 1.210$ & $\$ 1.246$ & $\$ 0.938$ & $\$ 0.966$ & $\$ 0.995$ & $\$ 1.025$ & $\$ 1.055$ & $\$ 1.087$ & $\$ 1.120$ \\
\hline Stock Price / Sh. & $\$ 13.00$ & $\$ 13.20$ & $\$ 13.31$ & $\$ 13.39$ & $\$ 13.80$ & $\$ 14.21$ & $\$ 14.64$ & $\$ 15.08$ & $\$ 15.53$ & $\$ 15.99$ & $\$ 16.47$ \\
\hline Capital Gain \% & & $1.54 \%$ & $0.83 \%$ & $0.64 \%$ & $3.00 \%$ & $3.00 \%$ & $3.00 \%$ & $3.00 \%$ & $3.00 \%$ & $3.00 \%$ & $3.00 \%$ \\
\hline Dividend Yield & & $8.46 \%$ & $9.17 \%$ & $9.36 \%$ & $7.00 \%$ & $7.00 \%$ & $7.00 \%$ & $7.00 \%$ & $7.00 \%$ & $7.00 \%$ & $7.00 \%$ \\
\hline Overall Return & & $10.00 \%$ & $10.00 \%$ & $10.00 \%$ & $10.00 \%$ & $10.00 \%$ & $10.00 \%$ & $10.00 \%$ & $10.00 \%$ & $10.00 \%$ & $10.00 \%$ \\
\hline$\%$ Chg. In Assets & & $10.00 \%$ & $10.00 \%$ & $0.64 \%$ & $3.00 \%$ & $3.00 \%$ & $3.00 \%$ & $3.00 \%$ & $3.00 \%$ & $3.00 \%$ & $3.00 \%$ \\
\hline$\%$ Chg. In Profits & & $\mathrm{N} / \mathrm{A}$ & $10.00 \%$ & $-45.00 \%$ & $0.64 \%$ & $3.00 \%$ & $3.00 \%$ & $3.00 \%$ & $3.00 \%$ & $3.00 \%$ & $3.00 \%$ \\
\hline \% Chg. In Dividends & & $\mathrm{N} / \mathrm{A}$ & $10.00 \%$ & $3.00 \%$ & $-24.77 \%$ & $3.00 \%$ & $3.00 \%$ & $3.00 \%$ & $3.00 \%$ & $3.00 \%$ & $3.00 \%$ \\
\hline
\end{tabular}

\section{An Alternative Methodology}


Notice that the only problem we are experiencing is in the transition between the dividend growth regimes, not within the regimes. With this in mind, we advocate that dividends be modeled not in the traditional way by employing a finite number of multi-year dividend regimes, but rather by invoking an sequence of 1 year dividend regimes, each defined by their respective ROA and plowback ratios. By taking such an approach, a logically consistent and feasible dividend process is implied, and a logical stock price results. ${ }^{9}$

With specific values for the level of ROA and PB in each period, a student is easily able to iterate across time the following dividend generating mechanism:

1. Given a beginning of period level of productive assets, the ROA for the period implies a level of profit for the year,

2. From these profits a proportion is paid out as dividends, and the remainder is plowed back into productive assets - implying a level of productive assets in place at the end of the period.

This generates an infinite stream of dividends to be valued.

Of course the next step is to value the infinite stream of dividends. This can be done on a spreadsheet in a number of ways. The most obvious way is to approximate the stock price by employing the first 100 years or so of dividends, and then claim (and confirm as an exercise) that any additional value from all additional dividends is very small. This is a useful pedagogical exercise. However, it is likely that at some future date ROA, PB, and $r$ will have all reached constant levels, and in this case the Gordon Model can be employed to value this terminal-stage dividend stream. This approach yields an exact value for the stock.

\section{An Example}

Suppose Zisco, an upstart manufacturer of optical switching equipment, is currently in the early stages of growth, and has productive assets equal to $\$ 10 /$ share. The economy is healthy and expected to remain so for the foreseeable future. Demand for optical switching equipment is expected to be strong in the foreseeable term. Competing firms have just began to enter the market. Given this backdrop, Zisco is expected to earn a ROA of 20\%, 30\%, $30 \%$, and $30 \%$ in years $1,2,3$, and 4 respectively. Due to increased competition, Zisco's ROA is expected to decline linearly from $30 \%$ to $10 \%$ in the subsequent 4 year period. Thereafter the ROA is expected to remain constant at $10 \%$.

Prudently, Zisco will not pay dividends as long as its ROA exceeds the required discount rate of $10 \%$. Specifically, the payout ratio will increase from $0 \%$ in years 1 to 6 , to $20 \%$ in year 7 , and to $40 \%$ in year 8 and beyond. Figure 2 displays our assumptions regarding ROA and payout ratios over time. ${ }^{10}$

Given the assumptions portrayed in Figure 2, Table 3 reports the implications for profits, dividends, and stock prices over time.

Figure 2

\footnotetext{
${ }^{9}$ Additional economic motivation for employing the proposed approach comes from understanding that the firm faces (i) macroeconomic business cycles, and (ii) firm-specific life-cycles (i.e. start-up, growth, competition, and maturity) that vary through time. Therefore, it makes sense to allow operational efficiency (ROA) and dividend policy (plowback ratio) to vary through time in as flexible a manner as necessary.

${ }^{10}$ Notice that this example cannot be described in the traditional multi-stage framework.
} 


\section{Assumed levels of Payout Ratio and ROA for Zisco Example.}

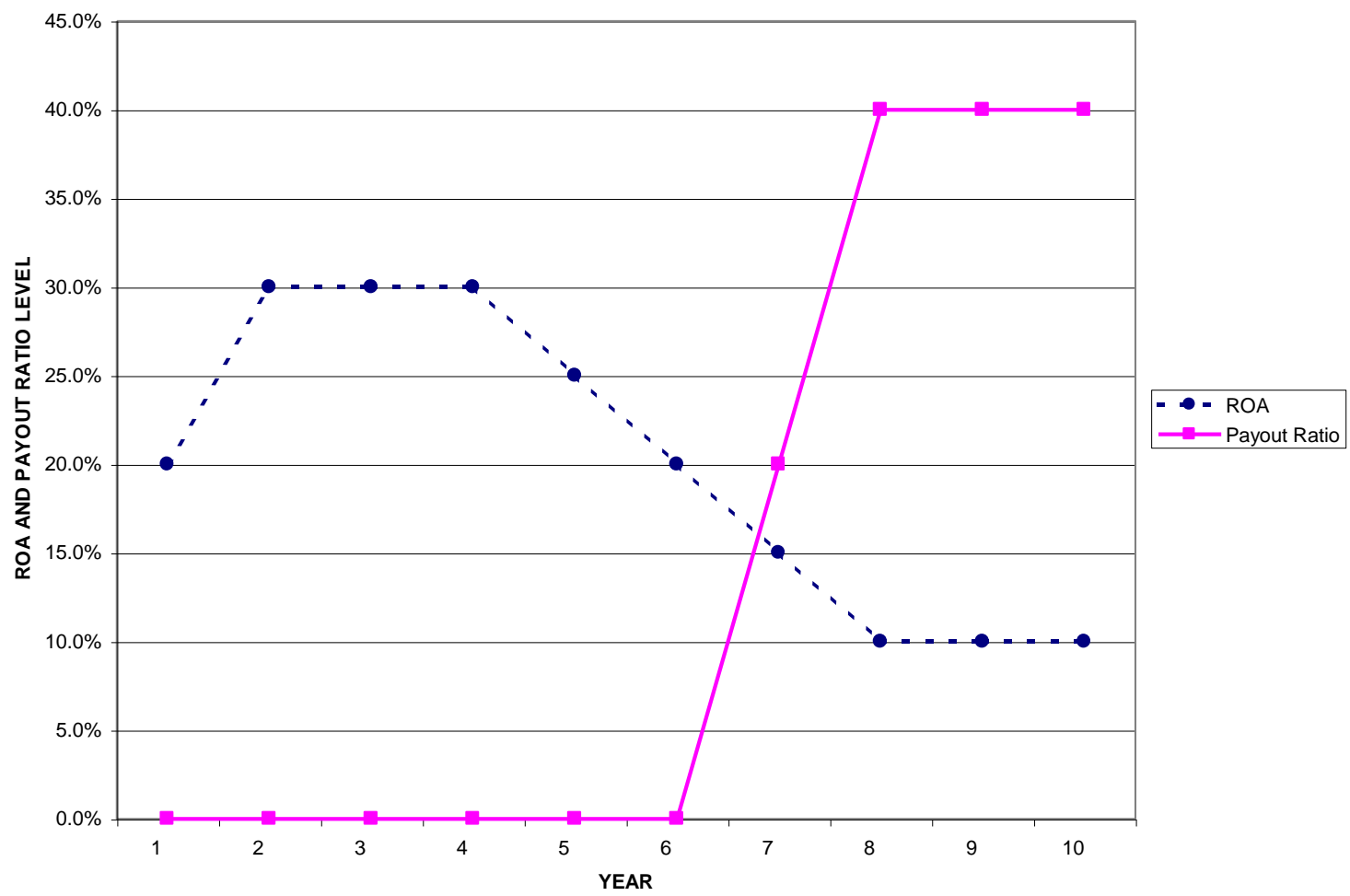

Table 3

Implied Dividend Stream and Stock Price Evolution for Zisco

\begin{tabular}{|c|c|c|c|c|c|c|c|c|c|c|c|}
\hline Time & 0 & 1 & 2 & 3 & 4 & 5 & 6 & 7 & 8 & 9 & 10 \\
\hline \multicolumn{12}{|l|}{ Assumptions: } \\
\hline ROA & & $20.0 \%$ & $30.0 \%$ & $30.0 \%$ & $30.0 \%$ & $25.0 \%$ & $20.0 \%$ & $15.0 \%$ & $10.0 \%$ & $10.0 \%$ & $10.0 \%$ \\
\hline Payout & & $0.0 \%$ & $0.0 \%$ & $0.0 \%$ & $0.0 \%$ & $0.0 \%$ & $0.0 \%$ & $20.0 \%$ & $40.0 \%$ & $40.0 \%$ & $40.0 \%$ \\
\hline Plowback (PB) & & $100.0 \%$ & $100.0 \%$ & $100.0 \%$ & $100.0 \%$ & $100.0 \%$ & $100.0 \%$ & $80.0 \%$ & $60.0 \%$ & $60.0 \%$ & $60.0 \%$ \\
\hline \multicolumn{12}{|l|}{ Calculations: } \\
\hline Assets $(\mathrm{t}-1)$ & $\$ 10.00$ & $\$ 12.00$ & $\$ 15.60$ & $\$ 20.28$ & $\$ 26.36$ & $\$ 32.96$ & $\$ 39.55$ & $\$ 44.29$ & $\$ 46.95$ & $\$ 49.77$ & $\$ 52.75$ \\
\hline$x \operatorname{ROA}(\mathrm{t})$ & & $20.0 \%$ & $30.0 \%$ & $30.0 \%$ & $30.0 \%$ & $25.0 \%$ & $20.0 \%$ & $15.0 \%$ & $10.0 \%$ & $10.0 \%$ & $10.0 \%$ \\
\hline$=\operatorname{Profit}(\mathrm{t})$ & & $\$ 2.000$ & $\$ 3.600$ & $\$ 4.680$ & $\$ 6.084$ & $\$ 6.591$ & $\$ 6.591$ & $\$ 5.932$ & $\$ 4.429$ & $\$ 4.695$ & $\$ 4.977$ \\
\hline x Payout(t) & & $0.0 \%$ & $0.0 \%$ & $0.0 \%$ & $0.0 \%$ & $0.0 \%$ & $0.0 \%$ & $20.0 \%$ & $40.0 \%$ & $40.0 \%$ & $40.0 \%$ \\
\hline = Dividends(t) & & $\$ 0.000$ & $\$ 0.000$ & $\$ 0.000$ & $\$ 0.000$ & $\$ 0.000$ & $\$ 0.000$ & $\$ 1.186$ & $\$ 1.772$ & $\$ 1.878$ & $\$ 1.991$ \\
\hline Stock Price / Sh. & $\$ 23.34$ & $\$ 25.67$ & $\$ 28.24$ & $\$ 31.06$ & $\$ 34.17$ & $\$ 37.59$ & $\$ 41.34$ & $\$ 44.29$ & $\$ 46.95$ & $\$ 49.77$ & $\$ 52.75$ \\
\hline Capital Gain \% & & $10.00 \%$ & $10.00 \%$ & $10.00 \%$ & $10.00 \%$ & $10.00 \%$ & $10.00 \%$ & $7.13 \%$ & $6.00 \%$ & $6.00 \%$ & $6.00 \%$ \\
\hline Dividend Yield & & $0.00 \%$ & $0.00 \%$ & $0.00 \%$ & $0.00 \%$ & $0.00 \%$ & $0.00 \%$ & $2.87 \%$ & $4.00 \%$ & $4.00 \%$ & $4.00 \%$ \\
\hline Overall Return & & $10.00 \%$ & $10.00 \%$ & $10.00 \%$ & $10.00 \%$ & $10.00 \%$ & $10.00 \%$ & $10.00 \%$ & $10.00 \%$ & $10.00 \%$ & $10.00 \%$ \\
\hline$\%$ Chg. In Assets & & $20.00 \%$ & $30.00 \%$ & $30.00 \%$ & $30.00 \%$ & $25.00 \%$ & $20.00 \%$ & $12.00 \%$ & $6.00 \%$ & $6.00 \%$ & $6.00 \%$ \\
\hline$\%$ Chg. In Profits & & $\mathrm{N} / \mathrm{A}$ & $80.00 \%$ & $30.00 \%$ & $30.00 \%$ & $8.33 \%$ & $0.00 \%$ & $-10.00 \%$ & $-25.33 \%$ & $6.00 \%$ & $6.00 \%$ \\
\hline$\%$ Chg. In Dividends & & $\mathrm{N} / \mathrm{A}$ & $0.00 \%$ & $0.00 \%$ & $0.00 \%$ & $0.00 \%$ & $0.00 \%$ & $\mathrm{~N} / \mathrm{A}$ & $49.33 \%$ & $6.00 \%$ & $6.00 \%$ \\
\hline
\end{tabular}

Although interpretation of Table 3 is straightforward, a few points should be made clear to students: 
1. In each period the overall rate of return to the investor is $10 \%$, the assumed fair rate of return. This is comprised of (i) the capital gain associated with the change in price of the stock, and (ii) the dividend yield. In the early years when no dividends are paid, the return is solely in the form of capital gains. In the "mature" years (beginning in the $8^{\text {th }}$ year) the capital gain percentage is always $6 \%$, and hence the dividend yield is always $4 \%$.

2. Prior to the final dividend growth stage, the growth rate of dividends is not equal to ROA.PB. If we were to impose in the first 8 years that the growth rate of dividends must equal ROA.PB, this would be tantamount to committing the error at the heart of our criticism. For the final dividend growth stage (year 9 to infinity) ROA $\cdot \mathrm{PB}=0.06$, hence assets, profits, and dividends all grow at a constant $6 \%$ growth rate.

3. In the first 7 years ROA is greater than the discount rate of $10 \%$. In such a case it is better to defer paying dividends until the end of year 7. Such a dividend policy allows the firm to grow their base of highly productive assets at high rates in the early years. That is, any dividend policy that pays dividends whenever ROA > $r$ cannot maximize the stock price, and hence is an inferior dividend policy. In addition, after year 7 (in which $\mathrm{ROA}=\mathrm{r}$ ) any dividend policy with a payout ratio greater than zero will result in the same stock price. In this case the firm's internal operations are earning the fair return required by investors, and investors are indifferent to earning $10 \%$ in the firm's internal operations or earning $10 \%$ on a similar risk investment. That is, for $\mathrm{ROA}=\mathrm{r}$, investors are indifferent to dividend policy.

\section{Conclusion}

Current stock pricing convention assumes that the first dividend in a latter stage of dividend growth is a pre-specified multiple of the last dividend in the previous stage of growth. With such an approach, if dividend generation is motivated from the commonly assumed dividend growth process of $g=\mathrm{ROA} \cdot \mathrm{PB}$, then the underlying assumptions are violated and the resulting stock valuation is erroneous.

We have proposed an alternative methodology for stock valuation which is internally consistent with assumed levels of operational efficiency (ROA) and dividend policy (PB) and hence, results in valuations consistent with the underlying assumptions. This internally consistent stock valuation can be obtained two different ways. First, one can abandon the traditional problem formulation in which only 2 or 3 stages of multi-year dividend growth are assumed, and instead allow each year to generate a dividend based upon the ROA, payout ratio, and assets in place at that time. This method provides a flexible structure for depicting operational efficiency and dividend policy over time, and is better able to capture the actual macroeconomic and firm-specific cycles that firms are exposed to. Second, if only a few multi-year ROA-PB stages are specified, then the traditional approach can be still employed as long as the first dividend in any new stage of dividend growth is computed based upon the new ROA and plowback ratio, and the assets in place at the beginning of the stage.

Pedagogically, when the proposed approach is contrasted with the traditional approach, the student is forced to develop a deeper fundamental understanding of how stock valuation relates to (i) operational efficiency, (ii) dividend policy, and (iii) the economic environment in which the firm competes.

\section{References}

1. Brealey, Richard, and Stewart Myers, 2000, Principles of Corporate Finance, $6^{\text {th }}$ ed., McGraw-Hill Irwin

2. Brealey, Richard, Stewart Myers, and Alan Marcus, 2001, Fundamentals of Corporate Finance, $3^{\text {rd }}$ ed., McGraw-Hill Irwin.

3. Brigham, Eugene, and Joel Houston, 1999, Fundamentals of Financial Management, $8^{\text {th }}$ ed., Dryden Press.

4. Brigham, Eugene and Michael Ehrhardt, 2002, Financial Management, Theory and Practice, $1^{\text {st }}$ ed., Harcourt College Publishers.

5. $\quad$ Chambers, Donald, and Nelson Lacy, 1999, Modern Financial Management, Theory and Practice, $2^{\text {nd }}$ ed., Addison Wesley.

6. $\quad$ Emery, Douglas, and John Finnerty, 1997, Corporate Financial Management, Prentice Hall.

7. Emery, Douglas, John Finnerty, and John Stowe, 1998, Principles of Financial Management, $3^{\text {rd }}$ ed., Pren- 
tice Hall.

8. Gordon, Myron, 1962, The Investment, Financing, and Valuation of the Corporation, Irwin Publishing.

9. Hickman, Kent, Hugh Hunter, and John Byrd, 2002, Foundations of Corporate Finance, $2^{\text {nd }}$ ed., SouthWestern

10. Lasher, William, 2000, Practical Financial Management, $2^{\text {nd }}$ ed., South-Western.

11. Levy, Hiam, 1998, Principles of Corporate Finance, South-Western.

12. Lewellen, Wilbur, John Halloran, and Lanser Howard, 2000, Financial Management, An Intro to Principles and Practice, South-Western.

13. Moyer, Charles, James McGuigan, and William Kretlow, 2001, Contemporary Financial Management, $8^{\text {th }}$ ed., South-Western.

14. Van Horne, James, 1998, Financial Management and Policy, $11^{\text {th }}$ ed., Prentice Hall.

Notes 
